\begin{tabular}{|c|c|c|}
\hline Case Reports in & \multicolumn{2}{|c|}{ Case Rep Gastroenterol 2019;13:508-513 } \\
\hline Gastroenterology & $\begin{array}{l}\text { DOI: 10.1159/000495207 } \\
\text { Published online: December 6, } 2019\end{array}$ & $\begin{array}{l}\text { (c) } 2019 \text { The Author(s) } \\
\text { Published by S. Karger AG, Basel } \\
\text { www.karger.com/crg }\end{array}$ \\
\hline & $\begin{array}{l}\text { This article is licensed under the } \\
\text { International License (CC BY-NC) } \\
\text { Usage and distribution for commercia }\end{array}$ & $\begin{array}{l}\text { nons Attribution-NonCommercial } 4.0 \\
\text { ger.com/Services/OpenAccessLicense). } \\
\text { uires written permission. }\end{array}$ \\
\hline
\end{tabular}

\title{
Massive Gastrointestinal Bleeding from a Jejunal Dieulafoy Lesion: An Extraordinary Presentation
}

\author{
Majdi Saada ${ }^{a, b}$ Shay Perek ${ }^{a} \quad$ Mohammad Agbaria $^{a}$ \\ Ayelet Raz-Pasteur ${ }^{a, b}$ \\ aDepartment of Internal Medicine A, Rambam Health Care Campus, Haifa, Israel; \\ ${ }^{b}$ The Bruce Rappaport Faculty of Medicine, Technion Israel Institute of Technology, \\ Haifa, Israel
}

\section{Keywords}

Dieulafoy lesion · Gastrointestinal bleeding · Jejunum · Scintigraphy

\begin{abstract}
We present an atypical and rare case of a previously healthy 27-year-old male who presented with acute onset of abdominal pain, bloody diarrhea, and syncope. At the Emergency Department, vital signs were stable with no signs of shock. Physical examination revealed diffuse tenderness of the abdomen and cherry red blood was noted upon rectal examination. Blood tests showed marked leukocytosis without anemia. Sigmoidoscopy was performed which revealed hematochezia with no obvious site of bleeding. The patient was admitted to the hospital with a working diagnosis of dysentery and received supportive care. During the following days, blood tests revealed an ongoing decline of hemoglobin levels which necessitated a new workup of gastrointestinal bleeding. Investigation modalities including upper and lower endoscopies as well as angiography failed to demonstrate a bleeding site. Scintigraphy, which was performed next, demonstrated an increased radiotracer activity in the right abdomen consistent with small bowel bleeding. Following these results, the patient underwent urgent laparotomy and surgical resection was performed. The histopathological findings were consistent with a Dieulafoy lesion. This case illustrates the importance of the complementary role of various modalities in locating the bleeding site along the gastrointestinal tract.
\end{abstract}




\section{Introduction}

Dieulafoy lesion (DL), which was first described by Gallard in 1884 and named after Dieulafoy in 1898, is one of the rare etiologies (1.3\%) of massive gastrointestinal (GI) bleeding associated with a high mortality rate [1]. The predominant characteristic of DL is a persistently large pulsatile caliber artery, 1-3 mm in size, which runs a tortuous path through the submucosa, with histologically normal surrounding mucosa and increased vascular wall fibrosis $[2,3]$. The diagnosis and localization of DL during massive bleeding are both important and difficult. The anatomical distribution of DL includes the stomach (71\%), duodenum (15\%), esophagus (8\%), rectum $(2 \%)$, colon $(2 \%)$, and jejunum $(1 \%)[4,5]$.

The most frequently used diagnostic modalities are endoscopy, angiography, and scintigraphy. Surgery is the treatment of choice in only $5 \%$ of patients and performed when endoscopic and angiographic attempts have failed [5].

We present a rare case of massive lower GI bleeding in a 27-year-old man. After diagnostic failures of endoscopic and angiographic interventions, localization of the bleeding site was achieved using scintigraphy followed by surgical resection. Final histopathological findings revealed a DL of the jejunum.

\section{Case Description}

A previously healthy 27-year-old male presented with acute onset of abdominal pain, bloody diarrhea, and syncope. His symptoms had begun $3 \mathrm{~h}$ prior to the Emergency Department (ED) visit, after eating at a local restaurant. On examination at the ED, the patient appeared well, vital signs included a temperature of $36.7^{\circ} \mathrm{C}$, blood pressure of $118 / 85 \mathrm{~mm} \mathrm{Hg}$, pulse 84 beats per minute, and oxygen saturation was $100 \%$ while he was breathing ambient air. Abdominal examination revealed diffuse tenderness of the abdomen and cherry red blood was noted upon rectal examination with no signs of organomegaly, rebound tenderness, or ascites. The remainder of the physical examination including neurological examination was normal. Blood tests revealed a total white blood cell count of 17,000 with $83 \%$ neutrophils, hemoglobin levels of $13 \mathrm{~g} / \mathrm{dL}$, and a normal platelet count. Other blood tests including levels of glucose, calcium, potassium, sodium, magnesium, phosphorus alanine aminotransferase, aspartate aminotransferase, alkaline phosphatase, total bilirubin, direct bilirubin, vitamin $B_{12}$, $\mathrm{C}$-reactive protein, and renal-function tests were within the normal range limits.

Sigmoidoscopy was performed and revealed hematochezia with no obvious site of bleeding. The patient was admitted to the internal medicine ward with a working diagnosis of dysentery. The following day, the patient was treated with fluid resuscitation and antibiotics. Hemoglobin level dropped to $11.1 \mathrm{~g} / \mathrm{dL}$ from a baseline of $13 \mathrm{~g} / \mathrm{dL}$, which was attributed to a hemodilution effect. On day 3 of hospitalization, blood tests revealed an ongoing decline of hemoglobin levels, which necessitated a workup of a massive GI bleed. The next morning, the patient underwent urgent upper and lower endoscopies which failed to demonstrate a source of bleeding. Angiography was the next modality to be performed and again there was no evidence of a bleeding site.

In light of a working diagnosis of a life-threatening bleeding, a decision was made to proceed to $\mathrm{Tc}^{99 \mathrm{~m}}$ red blood cell (RBC) scintigraphy, which demonstrated an early focus of increased radiotracer activity in the right lower quadrant which appeared to accumulate and ascend the right abdomen in a pattern consistent with small bowel bleeding (online suppl. Video 1, 2; for all online suppl. material, see www.karger.com/doi/10.1159/000495207). 


\section{Case Reports in Gastroenterology}

Case Rep Gastroenterol 2019;13:508-513

DOI: 10.1159/000495207

c) 2019 The Author(s). Published by S. Karger AG, Basel www.karger.com/crg

Saada et al.: Massive Gastrointestinal Bleeding from a Jejunal Dieulafoy Lesion: An Extraordinary Presentation

There was also milder uptake in the left abdomen that also accumulated throughout the study. Following these results, the patient underwent emergent laparotomy which demonstrated the bleeding site in the jejunum (Fig. 1). A surgical resection was performed, and the specimen was sent for further pathology investigation. The patient's medical condition improved gradually the following days and he was discharged home on day 5 postoperatively. The histopathological findings were consistent with a DL (Fig. 2).

On follow-up 3 months after surgery, the patient was doing well, with no recurrent bleeding or related symptoms.

\section{Discussion}

DL can be associated with massive, life-threatening hemorrhage and accounts for 1-2\% of cases of major GI bleedings [3-5]. Due to the possibility of massive recurrent bleeding, the mortality rate is high if not managed properly. The mechanism of DL's rupture is unclear. One theory suggests that the path of a DL runs in close proximity to the overlying mucosa; thus, DL's pulsations may disrupt said epithelium, leading to localized ischemia, erosion of the mucosa, and rupture of the artery [4]. DL of the jejunum is extraordinarily rare, with only a small number of cases reported to date [6-8]. This lesion is often seen in elderly, male patients with multiple comorbidities who are treated with non-steroidal anti-inflammatory drugs (NSAIDs), aspirin, or warfarin [5,6]. The mean age at presentation is over 50 years [6, 7]. DL is more prevalent in men than women. Other etiologies of DL include alcoholism, stress, cardiac or pulmonary failure, and fecalomas. According to previously published studies, over $80 \%$ of patients with DL had associated diseases [8].

In our case, the patient did not have any of these mentioned characteristics, which rendered DL quite low in the differential diagnosis at ED presentation. The leading presenting symptom is recurrent massive bleeding, including hematemesis, melena, and hematochezia and resulting hemorrhagic shock $[7,9]$.

The small size of the lesion and extensive blood and/or clot formation in the lumen make the diagnosis challenging. Diagnosis is even more complex as the bleeding stops. Thus, a repeated endoscopy, which is the most sensitive and cost-effective method, may be required [8]. If upper and lower endoscopies fail to locate the site of bleeding, or the bleeding is beyond the reach of therapeutic endoscopy, angiography is usually performed to localize the bleeding. It might need to be repeated as DL bleeds intermittently and sometimes can be missed as in our case $[6,9]$.

The relatively stable persistence of $\mathrm{Tc}^{99 \mathrm{~m}} \mathrm{RBCs}$ in the blood pool enables intermittent (and venous) bleeding to be detected, making RBC scintigraphy unique among diagnostic imaging methods in that it allows for monitoring of patients with an intermittent pattern of bleeding [10].

Tc ${ }^{99 m}$ RBCs accurately localize the site of bleeding in $88-97 \%$ of patients, with positive findings resulting in a 5-fold greater likelihood that the patient will require surgery [11]. RBC scintigraphy is often performed with the aim of determining a sufficient rate of bleeding to facilitate successful angiography and possible angiographic intervention [12]. A positive RBC scintigraphy study increases the likelihood of a positive angiogram from $22-53 \%$. Among the advantages of RBC scintigraphy versus angiography are the 10 -fold greater sensitivity for detection of slow bleeding rates or chronic bleeding lesions and the ability to examine the entire lower GI tract simultaneously and continuously over an extended period of time (60-90 min). Many angiographers prefer to have RBC scintigraphy prior to the contrast study to ensure that 
bleeding is active, i.e., the contrast study is more likely to identify the bleeding site if scintigraphy is positive. RBC scintigraphy plays an important role in the diagnosis of small intestinal bleeding, when conventional endoscopy (EGD, push enteroscopy, and colonoscopy) has limited value, and costly innovative methods, such as capsule endoscopy and double-balloon enteroscopy, are not readily available [13].

In our case, evaluation by esophagogastroduodenoscopy, colonoscopy as well as angiography all failed to show any abnormal bleeding site; thus, a decision was made to proceed to RBC scintigraphy prior to proceeding to the surgical treatment which is considered the last resort after failure of the aforementioned techniques [14]. Minimally invasive surgery is an option for DL, especially in the jejunum, but it needs preoperative localization. In our case, it was not possible, as the patient deteriorated hemodynamically. Despite the advantages of low rebleeding rates and definitive treatment option, surgery should be considered only after failure of therapeutic endoscopy and angiographic interventions and should be guided by perior preoperative localizations.

Therapeutic options for DL include endoscopic, angioembolization, and surgical resection. Deep enteroscopy is the preferred technique to treat hemodynamically unstable patients suspected of small-bowel DL $[15,16]$. The low incidence of DL makes it difficult to conduct large randomized control studies; thus, there are no clear guidelines on the best endoscopic techniques to treat DL. Epinephrine + heater probe (HP), argon plasma coagulation (APC), hemoclips (HCP), and epinephrine + HCP have all been used to treat DL in the small bowel [17, 18]. A retrospective study by Dulic-Lakovic et al. [15] demonstrated $100 \%$ initial hemostasis, $20 \%$ rebleeding, 2 resections, and no mortality [18]. Even though this study was small, HCP, Epinephrine + thermal methods, or Epinephrine + HCP had similarly effective hemostatic rates and safety profiles [19].

In summary, DL is an important cause of life-threatening bleeding. It is part of the differential diagnosis of upper or obscure GI bleeding, especially in patients who present with acute, massive, and intermittent upper GI bleeding [20]. Diagnosis and treatment options could pose a challenge - especially in young patients without known comorbidities, in whom the clinical presentation could mimic other more common medical conditions, thus necessitating the use of complementary diagnostic tools to accurately diagnose and localize the lesion.

\section{Statement of Ethics}

On behalf of all authors, I state hereby our commitment to integrity and honesty while writing the manuscript.

\section{Disclosure Statement}

The authors have no conflicts of interest to declare.

\section{References}

1 Gallard T. Aneurysmes miliaires de l'estomac, donnant lieu a des hematemeses mortelles. Bull Soc Med Hop Paris. 1884;1:84-91.

2 McGrath K, Mergener K, Branch S. Endoscopic band ligation of Dieulafoy's lesion: report of two cases and review of the literature. Am J Gastroenterol. 1999 Apr;94(4):1087-90. 
Saada et al:: Massive Gastrointestinal Bleeding from a Jejunal Dieulafoy Lesion: An Extraordinary Presentation

3 De Palma GD, Patrone F, Rega M, Simeoli I, Masone S, Persico G. Actively bleeding Dieulafoy's lesion of the small bowel identified by capsule endoscopy and treated by push enteroscopy. World J Gastroenterol. 2006 Jun;12(24):3936-7.

4 Nguyen DC, Jackson CS. The Dieulafoy's Lesion: An Update on Evaluation, Diagnosis, and Management. J Clin Gastroenterol. 2015 Aug;49(7):541-9.

5 Baxter M, Aly EH. Dieulafoy's lesion: current trends in diagnosis and management. Ann R Coll Surg Engl. 2010 Oct;92(7):548-54.

6 Lee YT, Walmsley RS, Leong RW, Sung JJ. Dieulafoy's lesion. Gastrointest Endosc. 2003 Aug;58(2):236-43.

7 Alshumrani G, Almuaikeel M. Angiographic findings and endovascular embolization in Dieulafoy disease: a case report and literature review. Diagn Interv Radiol. 2006 Sep;12(3):151-4.

8 Shin HJ, Ju JS, Kim KD, Kim SW, Kang SH, Kang SH, et al. Risk Factors for Dieulafoy Lesions in the Upper Gastrointestinal Tract. Clin Endosc. 2015;48(3):228-33.

9 Sai Prasad TR, Lim KH, Lim KH, Yap TL. Bleeding jejunal Dieulafoy pseudopolyp: capsule endoscopic detection and laparoscopic-assisted resection. J Laparoendosc Adv Surg Tech A. 2007 Aug;17(4):509-12.

10 Norton ID, Petersen BT, Sorbi D, Balm RK, Alexander GL, Gostout CJ. Management and long-term prognosis of Dieulafoy lesion. Gastrointest Endosc. 1999 Dec;50(6):762-7.

11 Currie GM, Kiat H, Wheat JM. Scintigraphic evaluation of acute lower gastrointestinal hemorrhage: current status and future directions. J Clin Gastroenterol. 2011 Feb;45(2):92-9.

12 Howarth DM. The role of nuclear medicine in the detection of acute gastrointestinal bleeding. Semin Nuc Med. 2006 Apr;36(2):133-46.

13 Tabibian JH. Technetium-99m-labeled RBC scintigraphy: less relative utility now than ever? J Clin Gastroenterol. 2011 Aug;45(7):651-2.

14 Chung IK, Kim EJ, Lee MS, Kim HS, Park SH, Lee MH, et al. Bleeding Dieulafoy's lesions and the choice of endoscopic method: comparing the hemostatic efficacy of mechanical and injection methods. Gastrointest Endosc. 2000 Dec;52(6):721-4.

15 Dulic-Lakovic E, Dulic M, Hubner D, Fuchssteiner H, Pachofszky T, Stadler B, et al.; Austrian Dieulafoybleeding Study Group. Bleeding Dieulafoy lesions of the small bowel: a systematic study on the epidemiology and efficacy of enteroscopic treatment. Gastrointest Endosc. 2011 Sep;74(3):573-80.

16 Ruff KC, Lunsford TN, Decker GA. An actively bleeding Dieulafoy's lesion. Clin Gastroenterol Hepatol. 2009 May; $7(5): e 22$.

17 Dy NM, Gostout CJ, Balm RK. Bleeding from the endoscopically-identified Dieulafoy lesion of the proximal small intestine and colon. Am J Gastroenterol. 1995 Jan;90(1):108-11.

18 Iacopini F, Petruzziello L, Marchese M, Larghi A, Spada C, Familiari P, et al. Hemostasis of Dieulafoy's lesions by argon plasma coagulation (with video). Gastrointest Endosc. 2007 Jul;66(1):20-6.

19 Sadio A, Peixoto P, Castanheira A, Cancela E, Ministro P, Silva A, et al. Dieulafoy's lesion in a duodenal diverticulum successfully treated with N-butyl-2-cyanoacrylate. Rev Esp Enferm Dig. 2010 Jun;102(6):3968.

20 Pasha SF, Hara AK, Leighton JA. Diagnostic evaluation and management of obscure gastrointestinal bleeding: a changing paradigm. Gastroenterol Hepatol (N Y). 2009 Dec;5(12):839-50. 


\section{Case Reports in Gastroenterology}

Saada et al.: Massive Gastrointestinal Bleeding from a Jejunal Dieulafoy Lesion: An Extraordinary Presentation

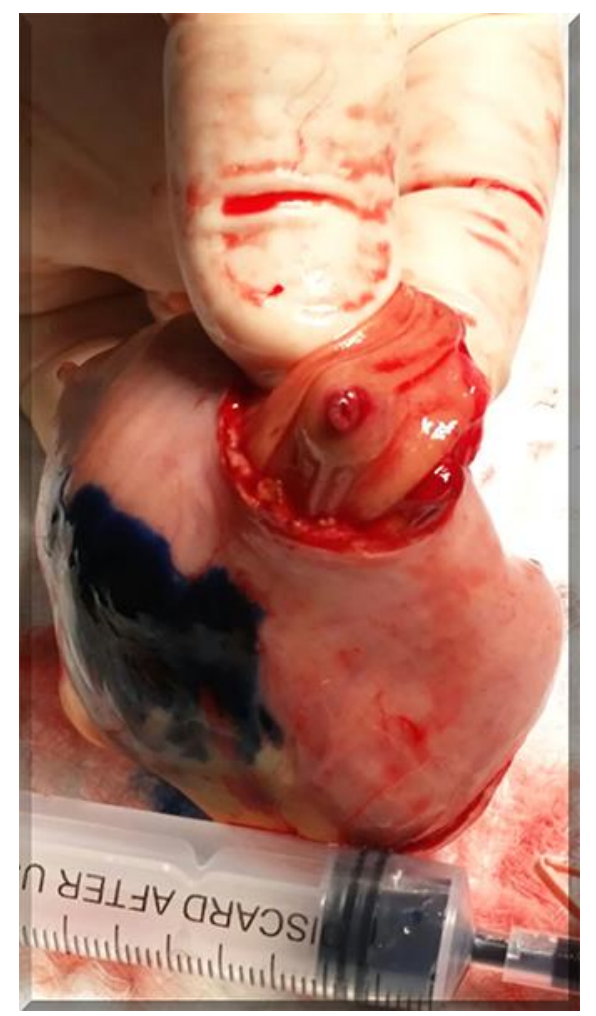

Fig. 1. Jejunal DL during urgent laparotomy: An intraoperative specimen from the jejunum demonstrating the source of bleeding.

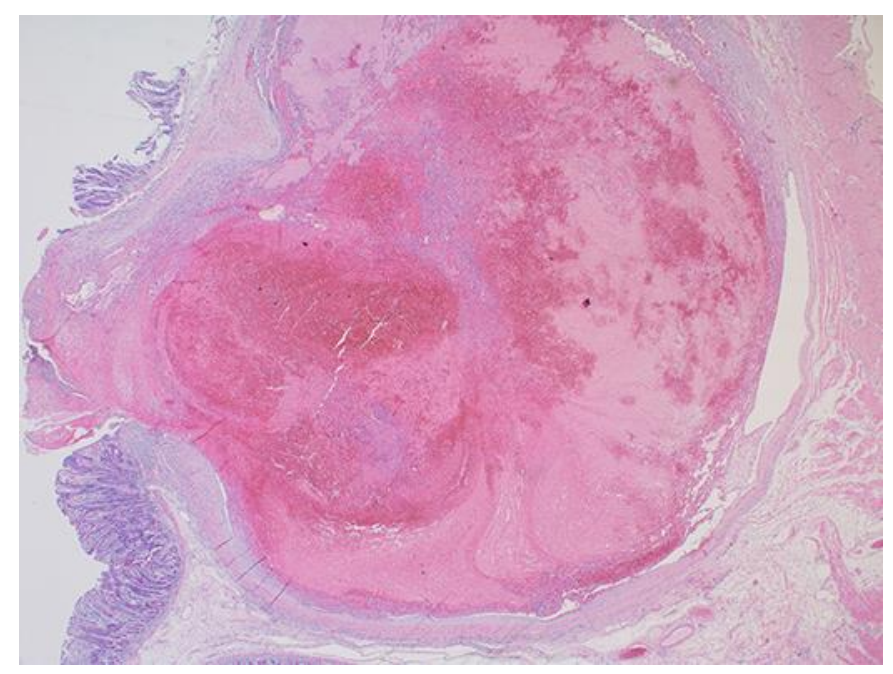

Fig. 2. Histopathological findings. Low magnification (objective lens $\times 2$ ) of hematoxylin and eosin-stained slides shows the presence of blood clot within the large tortuous, caliber-persistent artery through the overlying normal-appearing surrounding mucosa. 